LAWRENCE LIVERMORE N A T IO N A L LABORATORY
Critical Soil-Structure Interaction Analysis Considerations for Seismic Qualification of Safety Equipment

Quazi A Hossain

March 5, 2004

2004 ASME Pressure Vessel and Piping Conference San Diego, CA, United States

July 25, 2004 through July 29, 2004 
This document was prepared as an account of work sponsored by an agency of the United States Government. Neither the United States Government nor the University of California nor any of their employees, makes any warranty, express or implied, or assumes any legal liability or responsibility for the accuracy, completeness, or usefulness of any information, apparatus, product, or process disclosed, or represents that its use would not infringe privately owned rights. Reference herein to any specific commercial product, process, or service by trade name, trademark, manufacturer, or otherwise, does not necessarily constitute or imply its endorsement, recommendation, or favoring by the United States Government or the University of California. The views and opinions of authors expressed herein do not necessarily state or reflect those of the United States Government or the University of California, and shall not be used for advertising or product endorsement purposes.

This document was performed under the auspices of the U.S. Department of Energy by the University of California, Lawrence Livermore National Laboratory under Contract No. W-7405-Eng-48. 


\title{
CRITICAL SOIL-STRUCTURE INTERACTION ANALYSIS CONSIDERATIONS FOR SEISMIC QUALIFICATION OF SAFETY EQUIPMENT
}

\author{
Quazi A Hossain \\ Lawrence Livermore National Laboratory \\ Livermore, California, USA \\ Phone: (925) 423-2289 \\ E-mail: hossain1@IInl.gov
}

\begin{abstract}
While developing seismic analysis models for buildings that support safety-related equipment, a number of issues should be considered to ensure that the input motions for performing seismic qualification of safety-related equipment are properly defined. These considerations are listed and discussed here with special attention to the effect and importance of the interaction among the foundation soil, the building structure, the equipment anchors, and the equipment structure. Typical industry practices are critically examined to assess their adequacy for determining the input motions for equipment seismic qualification. The features that are considered essential in a soil-structure interaction (SSI) model are described. Also, the effects of inappropriate treatment or representation of these features are discussed.
\end{abstract}

\section{INTRODUCTION}

In the United States, safety-related equipment in nuclear and hazardous chemical facilities are required to be designed such that the equipment perform their safety function(s) during and following the design basis earthquake (DBE). The input seismic motion to which the safety-related equipment are qualified is determined from a seismic model of the building that often includes an approximate representation of the foundation soil or rock on which the building is located. This model is subjected to the design basis seismic acceleration time-history, and the resulting acceleration responses are calculated at various equipment support locations from which in-structure acceleration response spectra are generated. The equipment is then designed to withstand the motion that corresponds to the in-structure spectra applicable to the equipment location in the building.

The rigor with which the building and soil (or rock) analytical model is developed and the seismic analysis is performed determines the accuracy of the in-structure spectra. For these spectra to be accurate, a number of modeling issues must be considered. How these issues are typically addressed in the nuclear industry are briefly described and critically examined here. A number of recommendations follow.

\section{CURRENT PRACTICES}

The seismic motion from the bedrock propagates through the foundation soil or rock media and passes through building structures before causing the building supported equipment to vibrate. Hence, the motion at the equipment support location is highly affected by the dynamic characteristics of the soil or rock surrounding the building foundation and those of the building structure. To account for these effects, the seismic analysis models of facilities containing large inventory of radioactive materials or hazardous chemicals (e.g., commercial nuclear plants and DOE's Seismic Performance Category 3 and 4 facilities) include the soil or rock surrounding the building foundation [see references 1,2, and 3]. When properly analyzed, such a model, often called soil-structure interaction (SSI) model, accounts for not only the effect of soil or rock flexibility on the predicted responses at various building locations, but also accounts for the effects of the presence of the building on the input motion. But, for less hazardous facilities (e.g., DOE's PC-1 and PC-2 facilities), the effects of foundation soil or rock flexibility are either ignored or are approximately accounted for using crudely defined and not-so-transparent design factors. Also, for these lower category facilities, the effects of the presence of the building on the input motion are ignored [see references 4 and 5]. As a result, the seismic design conservatism of building structures and equipment in these lower category facilities is uncertain and not assured.

A "lumped mass" equivalent "stick" model is typically used to perform SSI analyses for PC-3, PC-4, and commercial nuclear power plant buildings. In such models, the building is idealized as a shear wall structure in which the "sticks," representing the composite effects of the building walls, are rigidly attached to the basemat. The soil or rock below the basemat and surrounding the 
basement walls are explicitly modeled. Acceleration responses at various elevations are computed from which in- structure spectra are generated for the purpose of performing equipment seismic qualification.

\section{LMITATIONS OF "STICK" MODELS IN SSI ANALYSES}

The limitations and shortcomings of the use of typical "stick" models in SSI analyses are discussed in the following paragraphs:

(a) "Stick" models are developed based on the assumption that the floors are rigid in the in-plane direction. For well laid out shear wall buildings this assumption is reasonable, and so are the resulting horizontal instructure spectra. But, for special purpose buildings with large cutouts in the floor diaphragms, this assumption is inappropriate and the in-plane flexibility of the floor diaphragms should be included. This would require a more explicit finite element model of the building walls and floor diaphragms (hereafter called an "Explicit" model in contrast to a "Stick" model).

(b) For equipment mounted on the wall at elevations/locations away from the floor, the instructure spectra for the out-of-plane motion of the wall cannot be determined directly from a "Stick" model in which the "Stick" typically represents the in-plane behavior of the walls parallel to the direction of motion. It is customary to determine the out-of-plane motion at wall locations away from the floors by performing a second-step analysis of the wall panel as a sub-structure and using the motion at the floor levels. This method introduces inaccuracies that can be significant depending on: (i) the extent of the wall panels and the floor panels adjacent to the subject location (where the in-structure spectra are being generated) that is included in the second-step analysis; (ii) the completeness of the input motion used in the secondstep analysis (Typically, only translational motion is used, but ignoring the rotational and torsional input may introduce significant error); and (iii) the method of accounting for the differences in the input motions at various boundaries of the substructure (An enveloping response spectrum, based on multiple input motions, should be generated, but that is not typically done, thus introducing some uncertainty).

(c) Each nodal mass and element in the "Stick" model represents a vast portion of the building to which a large number of fictitious single degree-of-freedom (SDOF) systems are attached for the purpose of generating in-structure spectra. Since these nodal masses and element stiffnesses are sometimes several orders of magnitude higher than those of the equipment attached to them, the equipment response, represented by the generated in-structure spectra do not include the correct interaction between the building structure and the equipment.

(d) The buildings in typical high hazard nuclear and chemical plants are often very complex structurally. The development of "Stick" models for the purpose of seismic analyses of such building and for determining building design loads and equipment input motions often require difficult judgments and questionable idealizations. The appropriateness of such judgments and idealizations can only be examined by comparing the results with those from an Explicit model

Even though these limitations are very severe and often distorts the input motions to which the safety related equipment are required to be seismically qualified, these were tolerated in the past because the use of an Explicit model of the building was not practical from the consideration of computer speed and capacity. But, with the introduction of much faster and more powerful computers, Explicit models are now well within the range of practicality.

\section{A CASE FOR DETAILED FINITE ELEMENT MODELS FOR SSI ANALYSES}

Even though the use of detailed finite element models (i.e., Explicit models) in the SSI analyses are no longer impractical, there seems to be a general reluctance to adopt these in the industry. The typical reasons given by those opposed to such use are as follows:

(a) The development of "Explicit" models is time consuming.

(b) Such models are more prone to human error.

(c) The results obtained from such complex models cannot be easily understood and interpreted.

The validity of these reasons are examined below:

(a) Compared to the time and effort necessary for developing "Stick" models, the development of "Explicit" models is actually less time consuming. Both models require the dimensions and data for each structural components, but the computation of the nodal masses; equivalent moments of inertia (translational, rotational and torsional); centers of mass; centers of rigidity; offsets; and contributions of discontinuous walls, that are needed for the "Stick" models require more manual effort than generation of finite element models which have been automatized in many structural analysis computer codes. These codes have been extensively used in the industry and their uses have been standardized to reduce the level of manual effort. Moreover, the development of finite element models follows a well defined and well practiced routine that do not require the level of attention and frequent judgments as is typically needed in developing "Stick" models.

(b) In the old days, when the structural analysis computer codes used to require manual input for each finite element, the "Explicit" models were more prone to human error. This is not so presently, because the data entry methods have been extensively automatized and many checks have been built into the codes. However, the potential for human error is still present in the "Explicit" models, but typically such errors are relatively easily detected by the built-in checks. On the other hand, since the development of "Stick" models requires frequent judgments and approximations, any error in making these judgments are often too subtle for detection by routine checks. 
(c) It is true that the results from "Explicit" models are more difficult to understand and interpret, but that is because the dynamic behavior of a complex structure that requires an "Explicit" model is also complex. The "Stick" model results are easy to interpret because such models are highly idealized, and often do not have any resemblance to the actual structure. The finite element method of structural analysis was developed primarily to rationally reduce, in a routine way, the errors that often result from the highly idealized and approximate models like the "Stick" models used in the seismic analyses. In fact, once the possibility of human errors is precluded through rigorous checks, the results from the "Explicit" models are the correct results.

\section{RECOMMENDATIONS AND CONCLUSIONS}

The current practice of using "Stick" models in seismic SSI analyses should be limited to lower safety category facilities (e.g., DOE's PC-1 and PC-2 facilities) and to well laid out buildings that have regular and full length shear walls and rigid (in-plane) floors with no or small cut outs. For high and moderate hazard facilities, detailed finite element models should be used in the seismic SSI analyses.

\section{REFERENCES}

1. American Society of Civil Engineers, Seismic Analysis of Safety-Related Nuclear Structures and Commentary, ASCE 4-98, 2000

2. United States Nuclear Regulatory Commission, Standard Review Plan for the Review of Safety Analysis Reports for Nuclear Power Plants, NUREG-0800, June 1987

3. United States Department of Energy, Natural Phenomena Hazards Design and Evaluation Criteria for Department of Energy Facilities, DOE-STD-1020 2002, January 2002

4. International Conference of Building Officials, Uniform Building Code, 1997

5. International Code Council, International Building Code, 2003 